ISBN 978-93-84468-94-1

International Conference on Education, Business and Management (ICEBM-2017)

Bali (Indonesia) Jan. 8-9, 2017

\title{
Factors Affecting Consumer Behavior on Choosing to Buy Bicycles in Capital District, Roi Ed Province
}

\author{
Advisor Dr. Chairat Suriyapa, and Saknatee Chompupuke \\ arjarnchairat@gmail.com \\ Post Graduate school of business Administration \\ Kasem Bundit University, Bangkok
}

\begin{abstract}
The primary purpose of this study is to determine factors affecting consumer behavior and marketing mix on choosing to buy bicycles in Capital district, Roi Ed Province. The samples were selected from 385 customers who used bicycles in Capital district, Roed Province by using a check list and rating scale questionnaire as a tool. Statistical application used for data analysis was frequency, percentage, mean, standard deviation, Chi-Square, and regression analysis. Findings indicated that most of respondents were males, age 30-40 years old, bachelor degree graduated, single marital status, government and state enterprise employees, and monthly average income 15,000-20,000 baht.Most of respondents owned bicycles before they bought the new ones for these reasons as follows: transportation to work, prices ranged between 10,000-20,000 baht, used bicycles during morning and evening hours, twice a week, and preferred bicycles weigh between 10-15 kilograms.The average picture of the opinions of factors affecting consumer behavior and marketing mix on choosing bicycles in capital district, Roi Ed province were at high level consisted of following reasons, such as products aspect, marketing promotion aspect, and distribution channel, respectively. Prices aspect was in medium level from the average picture of the opinions. As for factors of personal, such as age and occupation correlated with experienced bicycles shopping. As for personnel factors, such as occupation correlated with prices and frequency of bicycles usage per week. Factors of products and distribution channel correlated positively with consumer behavior on choosing to buybicycles in capitol district, Roi Ed Province.

Recommendations from the study were that store owners should offers wide range of bicycles brands, especially the popular brand names, sizes are not too big or too small, variety of color and beautiful styles, best quality accessories, should prioritize to longerservice warrantee, offers modern products with quality and ISO standards, prices appropriate to present economic circumstances, discount when pay in cash, longer repayment schedule, appropriate parts and labor charge, services dealers nationwide, suitable hours of operations, free gift with purchased, and advertising through multimedia.
\end{abstract}

\section{Introduction}

The history of bicycles built in Germany by Karl Drais in 1817. The technology was not complex which consisted of wheel, handle, and seat only. Afterward, the bicycle has developed to different models until 1878 which begin to use chain technology that help propelling the bicycle which make riding with stability. At present, there are many type of bicycles, such as mountain bicycle, road bicycle, stunt bicycle, hybrid bicycle, touring bicycle, city bicycle, fixed gear bicycle, and maid bicycle, etc. Some of the bicycles made from bamboo, Vietnam rattan, chromyl, steel, aluminum, scandium, carbon fiber, and titanium, and using 30 gears. The bicycle has been widespread in Thailand, in 2442 BC, when his Majesty King Chulalongkorn the Great, Rama V had held the country first bicycles for the first time at Wang Burapha pirom on the occasion of Chakrabongse Bhuvanath, Prince of Phitsanulok returned from Europe on July 9, 2442 BC.Journal of Head and Face Pain (2009) by Dr. Emma Varkey at Headache treatment 
center, Gothenburg City, Sweden. Studied on adult population, 68,000 people revealed that "People who do not exercise are prone to headaches increased 14 percent, cycling is useful because it helps to distribute oxygen and can reduce the frequency of headaches down 60 percent. From the BBC news has presented research that exercise help reduce the risk of heart disease and diabetes as well.

Cycling at high speed over 20 miles per hour in one hour, a person whose weight 130 pounds can burned up to 944 kilo calories, if a person weight 225 pounds will be able to burn calories for up to 1540 kilo calories and this is to show that how cycling can be great for energy metabolism. In current economic crisis which affects Thailand and countries around the world. Consumer pay higher prices for products than before. The increasing cost of living, people have to spend on the purchase of goods at higher prices, but the income is still the same. Fuel is considered a significant factor in human life, the high price of oil continue to affect consumers because people need to use oil when traveling with automobiles. In an economic like today, people can reduce expenses which more than necessary and need to balance their income, one option is to reduce travel cost by using bicycles for the short distance. As you can see that developed country like Japan people use bicycles for their traveling instead of automobiles which need oil to run. In addition, the tourism authority of Thailand has sponsored the traveling using bicycles in another way of travel which is to say that traveling by bicycles becoming popular among tourists who love adventure and want to protect the environment. Currently, Thailand has bicycles path along side with automobiles as well as organizing trips along various routes and remote area in every region.

People with different ages turned to more exercises, exercises affects the brain cell directly and makes the body pumping blood to bring oxygen to brain more efficiently. People who exercise have better health and can be cured of the diseases, cyclist Lance Armstrong has proven that he cured prostate, lung, and brain cancer with the bicycle exercise which motivate consumer to choose a bicycle for their alternative of exercise.

Therefore, the researcher believed that the study of factors affecting consumer behavior and marketing mix on choosing to buy bicycles in Capital district, Roi Ed Provincewill be very useful as a guideline to those who are interested in buying the bicycles, including the one who wants to ride a bicycle to travel to various locations as well. In addition, the information from this study will be used as a guideline for bicycle entrepreneur to develop their marketing plan in order to full fill customer requirements.

\section{The purpose of the study}

1. To study consumer behavior on choosing to buy bicycles in capital district, Roi Ed Province.

2. To study marketing mix factors affecting consumer behavior on choosing to buy bicycles in capital district, Roi Ed Province

\section{Conceptual frameworks of the study}

From the research and study above, researcher used consumer behavior and marketing mix theories to develop conceptual framework of the study. 


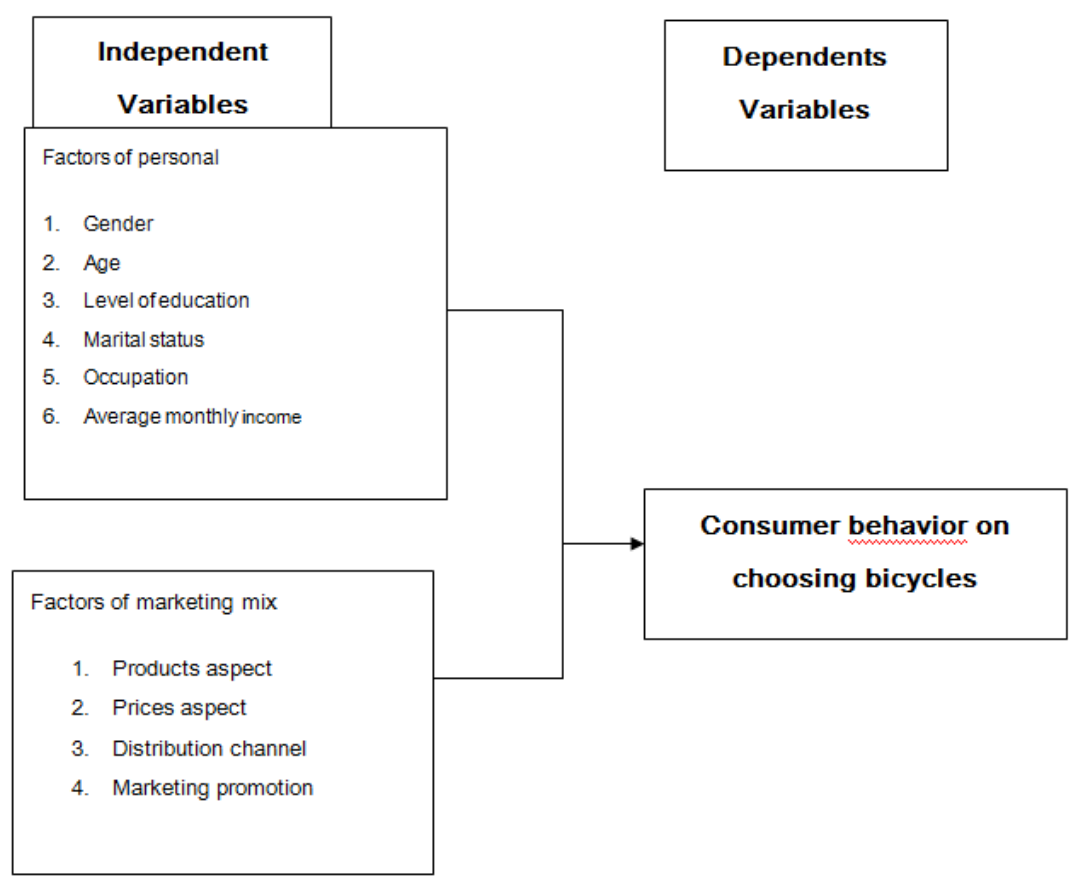

\section{Research Methodology}

\section{Sample selection}

The samples were selected from 385 customers who used bicycles in Capital district, Roi ed Province

\section{Data collection procedure}

The questionnaires were distributed to sample of 385 customers who used bicycles in Capital district, Roed Province. A total of 385 usable questionnaires were returned back to the researcher, yielding a 100 percent response rate and no missing data.

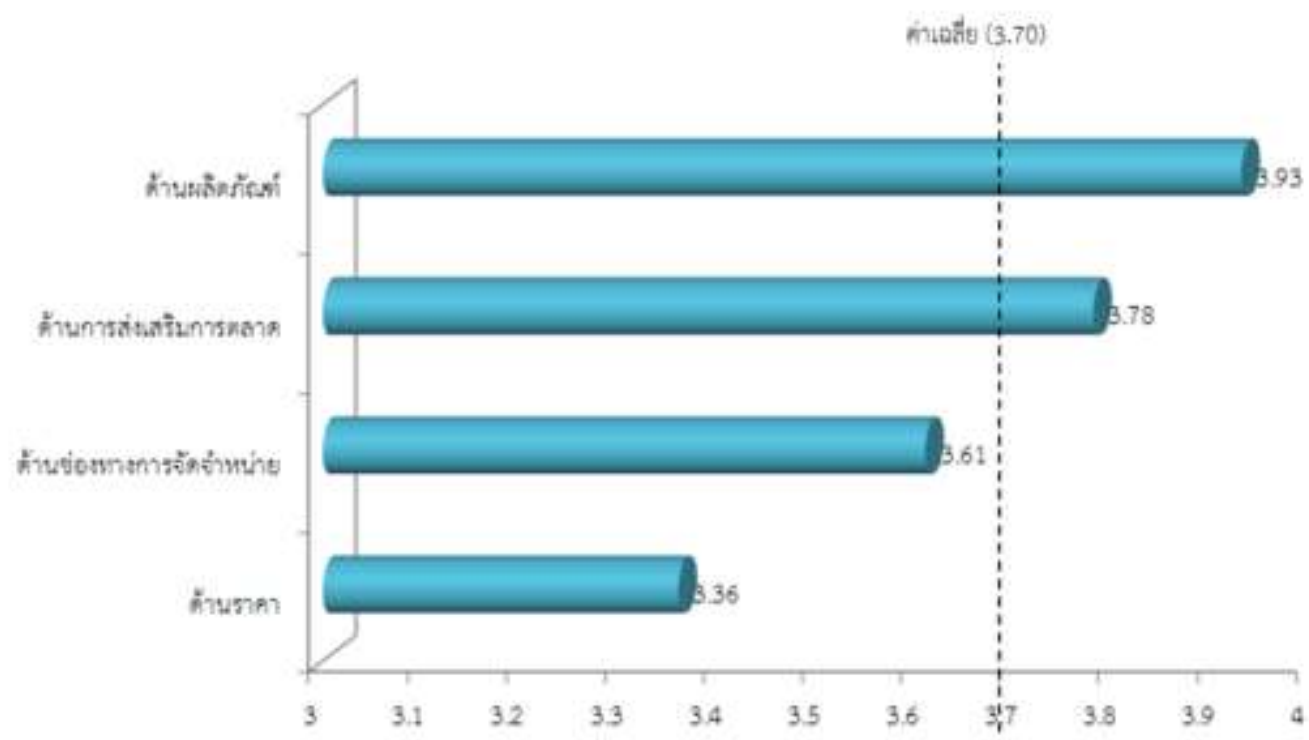

Fig. 1: shows results from study of the factors affecting consumer behavior and marketing mix on choosing to buy bicycles in Capital district, Roi Ed Province. 
From figure 1: shows the average picture of the opinions of the factors affecting consumer behavior and marketing mix on choosing to buy bicycles in Capital district, Roi Ed Province were in high level $(\bar{x}=3.70)$ when considered in each aspect found that the respondents prioritized on the factors affecting consumer behavior and marketing mix on choosing to buy bicycles in Capital district, Roi Ed Province were in high level with details as follows: products aspect $(\bar{x}=3.93)$, marketing promotion aspect $(\bar{x}=3.78)$, distribution channel $\bar{x}=(3.61)$, respectively, but prices aspect were at medium level $(\bar{x}=3.36)$ from the average picture of the opinion.

TABLE I: shows the results of hypothesis testing of relationship between marketing mix and consumer behavior on choosing to buy bicycles in capital district, Roi Ed Province.

\begin{tabular}{|c|c|c|c|c|c|}
\hline \multirow[t]{2}{*}{ Model } & \multicolumn{2}{|c|}{$\begin{array}{c}\text { Unstandardized } \\
\text { Coefficients }\end{array}$} & \multirow{2}{*}{$\begin{array}{c}\text { Standardized } \\
\text { Coefficients } \\
\text { Beta }\end{array}$} & \multirow[t]{2}{*}{$\mathrm{t}$} & \multirow[t]{2}{*}{ Sig. } \\
\hline & $\mathrm{B}$ & Std. error & & & \\
\hline (Constant) & 1.252 & .489 & & 2.561 & $.011 *$ \\
\hline Products aspect (X1) & .035 & .113 & .017 & .313 & $.044 *$ \\
\hline Prices aspect (X2) & .124 & .089 & .093 & 1.391 & .165 \\
\hline Distribution channel (X3) & .141 & .160 & .083 & .882 & $.018 *$ \\
\hline Marketing promotion (X4) & -.028 & .152 & .015 & -.186 & .852 \\
\hline
\end{tabular}

$\mathrm{R}=\mathrm{R}=0.155, \mathrm{R}$ Square $=0.024$, Adjusted R Square $=0.014$, Durbin-Watson $=1.746$

*Significant $0.05, * *$ Significant 0.01

The test of hypothesis revealed that the relationship between marketing mix and consumer behavior on choosing to buy bicycles in capital district, Roi Ed Province as follow details:

Independent variable $(\mathrm{X})$ is marketing mix factor consisting of products aspect (X1), prices aspect (X2), distribution channel aspect (X3), and marketing promotion aspect (X4).

Dependent variable (Y) is consumer behavior on choosing to buy bicycles in capital district, Roi Ed Province.

All factors of marketing mix are independent variables, be able to explain dependent variables are consumer behavior on choosing to buy bicycles in capital district, Roi Ed Province (Y) yielding 1.40 percent, by look at Adjusted R Square equal 0.014 and from analysis testing revealed that factor of products aspect (X1) and factor of distribution channel aspect (X3) correlated to consumer behavior on choosing to buy bicycles in capital district, Roi Ed Province (Y).

$\mathrm{Y}=1.252+(0.035)$ (products aspect) $+(0.141)$ (distribution channel) from linear regression analysis equation revealed that products aspect weight equal to 0.017 followed by distribution channel weight equal to 0.015 and revealed that factors of products and distribution channel aspect correlated in positive value with consumer behavior of choosing to buy bicycles in capital district, Roi Ed province with statistical significant 0.05 .

\section{Summary of study results}

The primary purpose of this study is to determine factors affecting consumer behavior and marketing mix on choosing to buy bicycles in Capital district, Roi Ed Province. The samples were selected from 385 customers who used bicycles in Capital district, Roi Ed Province by using a check list and rating scale questionnaire as a tool. Statistical application used for data analysis was frequency, percentage, mean, standard deviation, Chi-Square, and regression analysis.

From the data analysis results can be summarized as follows:

Findings indicated that the average picture of opinions of marketing mix factors affecting consumer behavior on choosing to buy bicycles in capital district, Roi Ed Province were in high level which consisted of products, marketing promotion, and distribution channel, but prices aspect with medium level on the opinion. 
Products aspect, revealed that the average picture of the opinions of factors affecting consumer behavior and marketing mix on choosing to buy bicycles in Capital district, Roi Ed Province were in high level as reasons to follow: bicycles styles, models, material used to make bicycles, performance, accessories, brand names, durable, available parts, color, and weight of bicycles was in medium level of the opinions.

Prices aspect, revealed that the average picture of the opinions of factors affecting consumer behavior and marketing mix on choosing to buy bicycles in Capital district, Roi Ed Province were in medium level as reasons to follow: maintenance fee, additional parts, financial plan, purchase with credit cards, discount prices, display prices label clearly.

Distribution channel, revealed that the average picture of the opinions of factors affecting consumer behavior and marketing mix on choosing to buy bicycles in Capital district, Roi Ed Province were in high level as reasons to follow: easy access to the shop, parking spaces available, repair center, located in the neighborhood, clean environment, fast service, customers lounge, longer hours of operation, attractive products display, respectively.

Marketing promotion, revealed that the average picture of the opinions of factors affecting consumer behavior and marketing mix on choosing to buy bicycles in Capital district, Roi Ed Province were in high level as reasons to follow: salesperson with service courtesy, fast service and right on the schedule, parts with longer warrantee, exchangeable products, products event shows at different places, free gift with purchased, advertising through multimedia, and service after sales, respectively.

Recommendations from the study were that store owners should offers wide range of bicycles brand names, especially the popular brand names, sizes are not too big or too small, variety of color and beautiful styles, best quality accessories, should prioritize to longer service warrantee, offers modern products with quality and ISO standards, prices appropriate to present economic circumstances, discount when pay in cash, longer repayment schedule, appropriate parts and labor charge, services dealers nationwide, suitable hours of operations, free gift with purchased, and advertising through multimedia.

\section{Suggestions for future research}

1. For the future research should focus on qualitative research for in-depth interview to bicycles users regarding factors affecting consumer behavior and marketing mix on choosing to buy bicycles in Capital district, Roi Ed Province.

2. For the future research should study on the obstacles and problems that occurs when using bicycle and result to be used as guidelines for the development of bicycle products, suitable to use in the future.

3. For the future research should study on the satisfaction of using bicycles of different brands, the results can be used as a guideline to improve marketing factors.

\section{References}

[1] Kulthorn Thonghum. (2552). Factors affecting consumer behavior on buying bicycles with automatic Gears in Pranakorn Sriayuthya province, Thesis, Master of Business Administration, Ratchaphat Pranakorn Sriayuthya, University.

[2] Chatyaporn Samurjai. (2550). Consumer behavior. Expertnet, Bangkok.

[3] Chommada Srinual. (2553). bicycling for people and tourists in Nakorn Songkla Municipality District: appropriate bicycles path and model. Thesis, Master of Science, Mahidol University.

[4] Bungorn Kampratete. (2540). Using marketing strategy to manage the Financial Institute Library Thesis, Master of Arts, Ramkamhaeng University.

[5] Boonna Noppakun. (2549). Consumer behavior on buying bicycles. Thesis, Master of Business Administration, Ratchaphat Thonburi University.

[6] Panisa Lunchanon. (2548). The Principle of marketing. Business work, Bangkok.

[7] Ronnachai Tantrakul. (2551). Products management. CK and folk studio, Bangkok.

[8] Luen Saiyos \& Associate. (2536). Research technique of education. $3^{\text {rd }}$ edition, Education supporting center, Bangkok.

[9] Vansiri Parnkosol \& Associate. (2542). Factors affecting consumer to ride bicycles in Lumpoon. 